\title{
A green autumn?
}

\author{
Stephen Hancocks OBE \\ Editor-in-Chief
}

The BDJ Upfront section includes editorials, letters, news, book reviews and interviews. Please direct your correspondence to the News Editor,

Kate Quinlan at k.quinlan@nature.com. Press releases or articles may be edited, and should include a colour photograph if possible.

$\mathrm{H}$ aving a global readership, it is perhaps no longer correct to reference seasons in terms of the northern hemisphere. Autumn here is the period of mellow fruitfulness, stealthily creeping morning mists and shortening daylight hours. However, although traditionally linked with hues of browns, golds and yellows, this fall is far more likely to be green; as in the burgeoning simultaneous spring of our southern hemisphere colleagues.

By the time that you read this, the United Nations (UN) General Assembly will have commenced the next round of debating its 2030 Agenda for Sustainable Development - this being one of the upcoming events heralded by the editorial in the previous $B D J$ issue, simultaneously published in hundreds of medical journals on climate change and health. Moving ahead to early November, the UN's COP Conference, hosted by the UK in Glasgow, is set to place attention on the wellbeing of planet and people by cutting fossil fuels, reducing air pollution and improving health worldwide. We are now familiar with the circus of media hype that surrounds such high-profile gatherings. Yet, we should take impetus from these stage-managed world moments to reflect on what we can do within our personal and professional lives to make a positive difference, a small contribution to global improvement.

As well as many initiatives on environmental matters, the $\mathrm{BDA}$ is also now a member of the UK Health Alliance on Climate Change. The BDJ Portfolio, guided by Springer Nature's sustainability policies, has been refining its use of materials and resources - most recently changing from plastic enveloping to recycled paper, for further recycling. Green dentistry is a matter that we have published on for some time, with a particularly valuable series of seven papers in 2019 by Duane and others. Many readers too have taken action by implementing changes in their practices, clinics and departments to reduce their carbon footprints. The dental industry is making great strides especially now creating recyclable toothbrushes and toothpaste tubes, but with many other green innovations.

The major contributor to carbon dioxide $\left(\mathrm{CO}_{2}\right)$ emission by dentistry is not the practice of it per se but from travel. Team members and patients travelling to and from practices as well as other supporting traffic making deliveries and collections account for a colossal $64.5 \%$ of dentistry's carbon emissions. ${ }^{1}$ So what about more interest in electric vehicles (EVs)? Greater utilisation of EVs seems like an obvious way in which dentistry could help substantially reduce its $\mathrm{CO}_{2}$ contribution and might achieve this in a variety of ways. To date, the emphasis has been on encouraging more panels and perhaps a battery pack to store the electricity generated, then you might also have room for a charger - in a practice car park, on a drive? Could the team utilise this? Could patients? Supermarkets are beginning to install these for the use of their customers, free of charge, and a range of accommodation venues such as motels, hotels and even Airbnb providers are also attracting EV owners' business for the very best of reasons. Perhaps we can also help by persuading suppliers to switch to EVs?

Early days perhaps? Not really. Various governments are putting in place policies for the phasing out of combustion vehicles within the next decade. That is probably only one 'next car' away, if that. Our human tendency

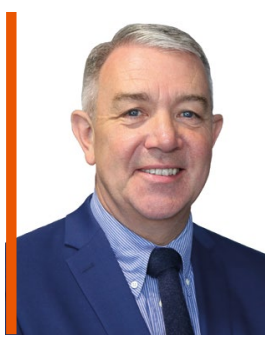

\section{'The dental industry is making great strides especially now creating recyclable toothbrushes and toothpaste tubes, but with many other green innovations.'}

walking, cycling and journey sharing, but this is of limited value for a wide range of practical reasons. The use of EVs solves many of these problems. Here, I have to declare that I am a recent convert. We now have an EV (which is fantastic; yes, really) and which is powered through an electric charger from solar panels on our garage roof, which also provide a high percentage of power used in the house. In the six months since its arrival, we have apparently saved nearly a metric ton of $\mathrm{CO}_{2}$ emissions, or the equivalent of 40 trees planted (I prefer this comparison) and have, quite genuinely, saved over $80 \%$ across our cost of energy.

One main message about EVs and charging is that everyone has different circumstances and various requirements. So too with dental practices. But if you have the space for solar is to put these decisions off until time has run out, but time is running out and we need to act. There is a growing body of information out there, especially on YouTube (Fully Charged, EVs Explained etc) to help ease us into the new normal of electric transport options. Apart from helping save the plant, improve health, reduce our professional and personal carbon footprints, and save money, we can now also drive around in autumn and spring powered by sunshine. Surely that is a colour to relish, whatever season one is in?

\section{References}

1. Duane B, Steinbach I, Ramasubbu D et al. Environmental DentJ 2019; 226: 525-530.

https://doi.org/10.1038/s41415-021-3516-8 sustainability and travel within the dental practice. $\mathrm{Br}$ 